\title{
Dose rate evaluation of workers on the operation floor in Fukushima-Daiichi Unit 3
}

\author{
Kaoru Matsushita ${ }^{1, *}$, Masahiko Kurosawa ${ }^{1}$, Keisuke Shirai ${ }^{2}$, Ippei Matsuoka ${ }^{3}$ and Naoki Mukaida ${ }^{3}$ \\ ${ }^{1}$ Toshiba Corporation, Yokohama, 235-8523, Japan \\ ${ }^{2}$ Tokyo Nuclear Services Corporation, Tokyo, 110-0016, Japan \\ ${ }^{3}$ Tokyo Electric Power Company Holdings, Inc. , Tokyo, 100-8560, Japan
}

\begin{abstract}
At Fukushima Daiichi Nuclear Power Plant Unit 3, installation of a fuel handling machine is planned to support the removal of spent fuel. The dose rates at the workplace were calculated based on the source distribution measured using a collimator in order to confirm that the dose rates on the operation floor were within a manageable range. It was confirmed that the accuracy of the source distribution was $\mathrm{C} / \mathrm{M}=$ 1.0-2.4. These dose rates were then used to plan the work on the operation floor.
\end{abstract}

\section{Introduction}

In Unit3, spent fuel assemblies remain in the spent fuel pool (SFP). These will be removed from the pool and transported to a common pool. To do this, a new fuel handling machine (FHM) and workplace for machine maintenance will be installed over the SFP (Figure 1). Because people will be in the workplace, dose rates in the workplace needed to be evaluated to check the plan.

However, the reactor building of Unit 3 was severely damaged by a hydrogen explosion. The ceiling, floor and wall from an operation floor located in the top of Unit 3 were collapsed, the fuel handling machine and beams had also fallen onto the operation floor (Figure 2). Large pieces of debris from the wall, ceiling, machines and so on, were strewn all over the operation floor. Because of the debris, measurements could not be done to accurately evaluate the dose rate at the workplace. Therefore the situation on the operation floor was unknown.

From September 2011 until November 2013 a crane was used to remove the large debris on the operation floor. Once complete it was discovered that the operation floor was a high dose area and most of the floor was fragile.

To quantify the radiation field at the operation floor measurements were needed to calculate the source strength and distribution. To take these measurements we designed a collimator with a detector suited to the operation floor. This collimator and detector were used to quantify the source distribution. Finally, using the evaluated source distribution, the radiation field and dose rates at the workplace were calculated.

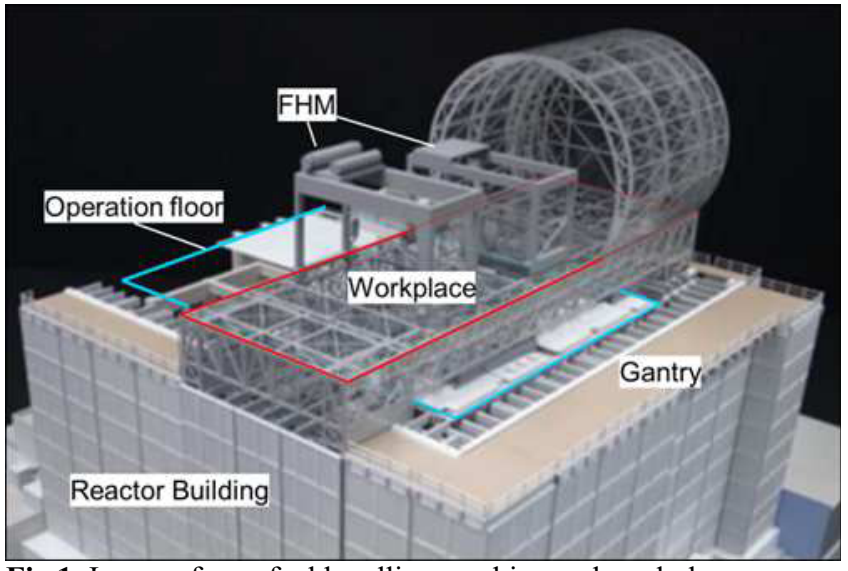

Fig.1. Image of new fuel handling machine and workplace

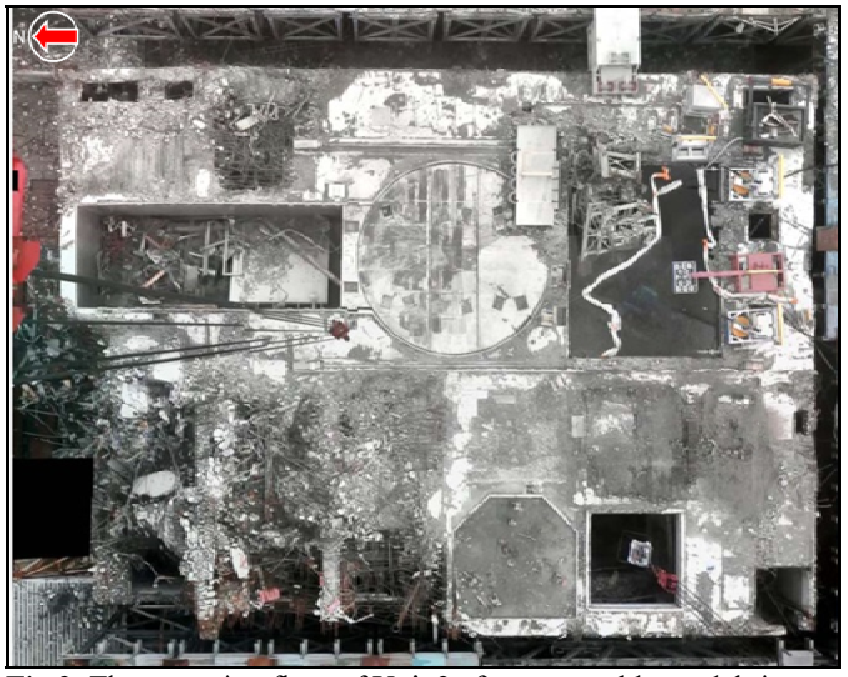

Fig.2. The operation floor of Unit 3 after removal large debris

2 Design of collimator

* Corresponding author: kaoru2.matsushita@toshiba.co.jp 


\subsection{Premise for designing collimator}

There were high dose areas on the operation floor after a removal of the large debris. It was assumed that the small debris remained on the operation floor were radioactive and penetrated into the concrete floor. In addition, the operation floor was unstable and, in particular, the floor on the northwest side has mostly collapsed (see Figure 2). Thus neither people nor machines could come close to the operation floor; dose measurement needed to be done using a crane.

To mitigate the time needed to perform measurements using a crane, a 4-meter-by-4-meter mesh with measurements taken $50 \mathrm{~cm}$ above the floor was used to quantify the radiation source. 130 measurement points were needed to cover the area of interest using this mesh size. The strength of the source in each mesh was calculated using the relationship between unit radioactivity on a mesh and the calculated dose rates at a detector.

Because the measured dose rates from a target mesh will include dose rates from the other mesh, a collimator was used to attenuate the radiation from other mesh. Measurement data was collected using a wireless system and a Geiger-Muller (GM) counter. The GM has already been used at the Fukushima site with a wireless system.

Due to the project schedule using a new collimator was not an option. A collimator which had already been made for another measurement needed to be used. A vertical cross-section of the collimator is shown in Figure 3. It has a rectangular shape casing made of steel, filled with concrete with a cylindrical hole through the center of the concrete for gamma ray attenuation. This collimator was able to measure the dose rates from an area around and under the collimator by fixing GM counter in the hole.

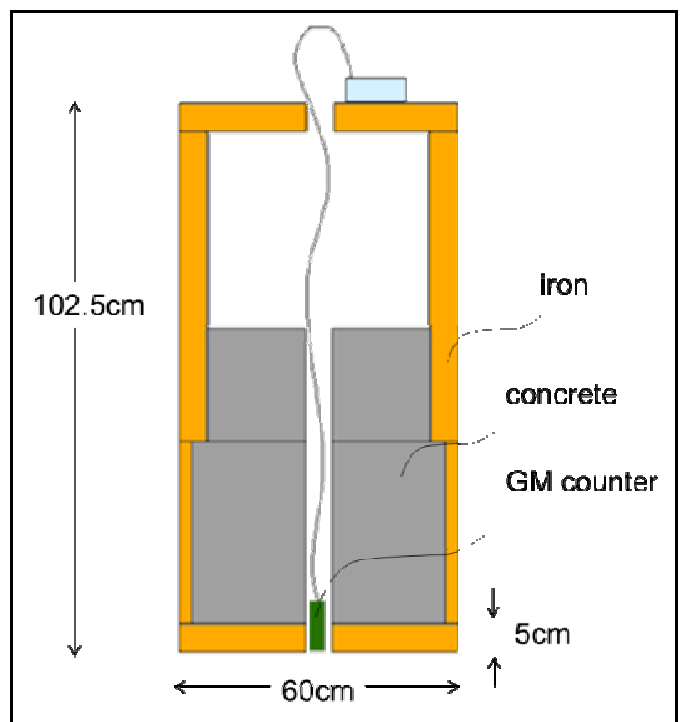

Fig.3. GM counter with the collimator

\subsection{Calculation condition for design collimator}

When measuring the dose rate from a target mesh, the results will include noise due to radiation from adjacent meshes. To understand the impact of noise from adjacent meshes, we examined the collimator configuration.

A disc-shape radiation source, with a radius of 400 $\mathrm{cm}$ and a uniform source strength, was assumed. The term $\mathrm{D}_{\text {total }}$ was defined as the dose rate from a radiation source in whole source region. The term $\mathrm{D}_{0-200}$ was defined as the dose rate from the source assuming a 200 $\mathrm{cm}$ radius. The ratio of $\mathrm{D}_{0-200}$ to $\mathrm{D}_{\text {total }}\left(\mathrm{D}_{0-200} / \mathrm{D}_{\text {total }}\right)$ was defined as a performance metric with a target value of over $0.99 ;$ a $\mathrm{D}_{0-200} / \mathrm{D}_{\text {total }}$ value of 0.99 means that the adjacent mesh provide $<1 \%$ of the dose rate measured by the collimator. Therefore, if the radiation sources of adjacent mesh are two orders of magnitude (100x) higher than the target mesh, then no more than half of the dose rate at the target mesh would be noise from adjacent mesh. This level of conservatism was considered acceptable.

A radiation concentration was set based on the highest measured dose rate on the operation floor and the gamma spectrum was assumed to be from Cs134, Cs137, and Ba137m. "MCNP5" [1] was used for calculations with "MCPLIB04" [2] as the photoatomic data library and the flux to dose conversion factor is based on "ICRP Publication 74"[3].

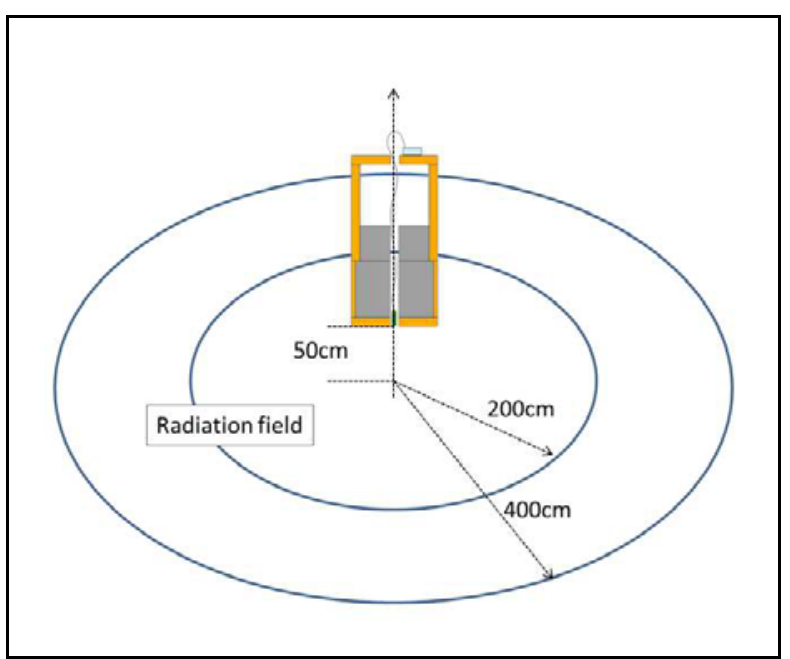

Fig.4. Calculation geometry for designing the collimator

\section{$2.3 \mathrm{D}_{0-200} / \mathrm{D}_{\text {total }}$ of improved configuration collimator}

The base case collimator shown in Figure 3, would have the GM counter set in the bottom of the hole since its $\mathrm{D}_{0 \text { - }}$ ${ }_{200} / \mathrm{D}_{\text {total }}$ was planned to be 0.99 . However, it was found that a dose rate at the bottom of the hole was over the upper limit of the GM counter, $1000 \mathrm{mSv} / \mathrm{h}$.

As a result, the GM counter was set in an upper region of the hole because the dose rate must be below the upper limit of the GM counter while maintaining the collimator configuration. However, $\mathrm{D}_{0-200} / \mathrm{D}_{\text {total }}$ was calculated to be 0.8 , indicating the concrete region of the collimator was insufficient to attenuate the gamma rays. Additionally, moving the GM counter higher in the collimator reduced the source area from which gamma rays could come into the detector directly. Therefore, the detector was returned to the bottom of the collimator to expand the solid angle from which gamma rays could 
directly enter the detector. A $5 \mathrm{~cm}$ iron plate was installed on the bottom surface of the collimator to attenuate the dose rate at the detector and a $10 \mathrm{~cm}$ iron plate was added onto the outside surface to improve gamma ray attenuation in the concrete region. With these alterations, $D_{0-200} / D_{\text {total }}$ was 0.97 . To increase the $D_{0 \text { - }}$ $200 / D_{\text {total }}$ score, we extended the side plate down below the bottom plane of the detector to reduce dose rate from source between $200 \mathrm{~cm}$ and $400 \mathrm{~cm}$ scattered from the floor. With the extended side panel, it was found that $\mathrm{D}_{0 \text { - }}$ ${ }_{200} / \mathrm{D}_{\text {total }}$ was 0.99 .

Relative dose rates maps are shown in Figure 5. The left map is a case of the base collimator and right map is an improved collimator. In both cases, the radius of the radiation source was set to $400 \mathrm{~cm}$ and the bottom of the collimator was located $50 \mathrm{~cm}$ above the floor. As the maps show, dose rates in the improved collimator were lower than in the basis collimator.

It was thought that the other configuration could effectuate the aim that $\mathrm{D}_{0-200} / \mathrm{D}_{\text {total }}$ was 0.99 . However, we decided to prioritize a schedule of this project and to adopt the improved collimator and GM counter.

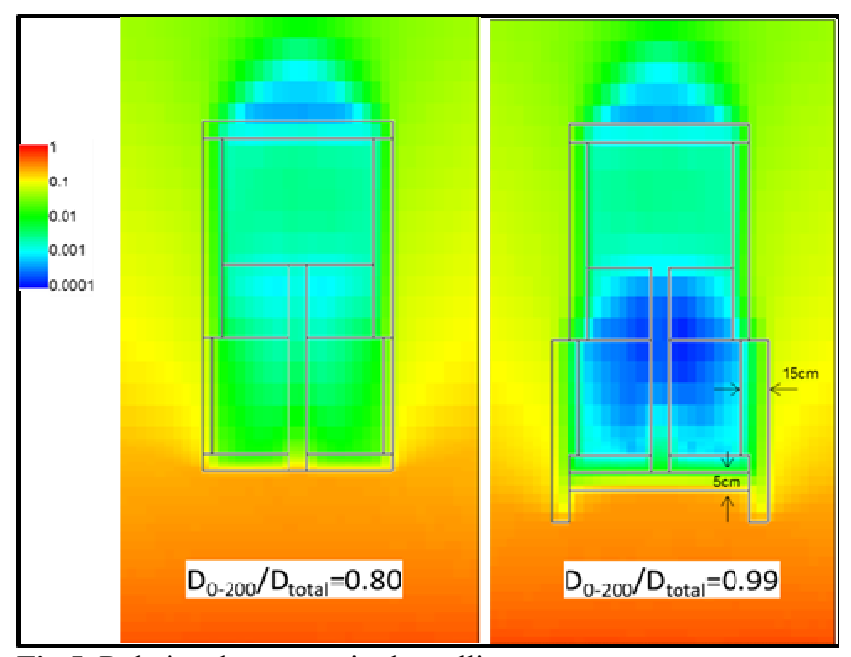

Fig.5. Relative dose maps in the collimator

This collimator and GM counter were hung $50 \mathrm{~cm}$ above the operation floor by a crane and a dose rate was measured at the each mesh. In addition, another unshielded GM counter was set $4.5 \mathrm{~m}$ above the GM counter in the collimator, i.e. at $5.0 \mathrm{~m}$ from the operation floor. Using this GM counter, unshielded dose rates at a distance of $5 \mathrm{~m}$ were obtained at the same time as the dose measurements at $50 \mathrm{~cm}$ with the collimator.

\section{Evaluation of source distribution}

\subsection{Procedure of evaluation of source distribution}

A flowchart showing how the evaluation of the source strength was calculated is shown in Figure 6. The source strength can be obtained using a relation between the target mesh which has a uniform source strength and a measured dose rate at the GM counter with the collimator. However the dose rate includes the dose rate from the adjacent mesh. Using the relationship between the adjacent mesh which have a uniform source strength and the dose rate at GM counter with the collimator, a dose rate from target mesh is obtained from the measurement dose rate. Therefore, the strength can be obtained using a relation of the target mesh and a dose rate at GM counter with the collimator.

Next, for variation of source strength, dose rates at 5 $\mathrm{m}$ from the operation floor wihout the collimator were calculated using the evaluated source strength. Ratios of caluculated dose rates at $5 \mathrm{~m}$ to measurement dose rates at $5 \mathrm{~m}$ obtained from $\mathrm{GM}$ counter $(\mathrm{C} / \mathrm{M})$ showed in 2.3 . If ranges of $\mathrm{C} / \mathrm{Ms}$ were over 2.0 or below 0.5 , evaluated radiation concentration would be re-evaluated.

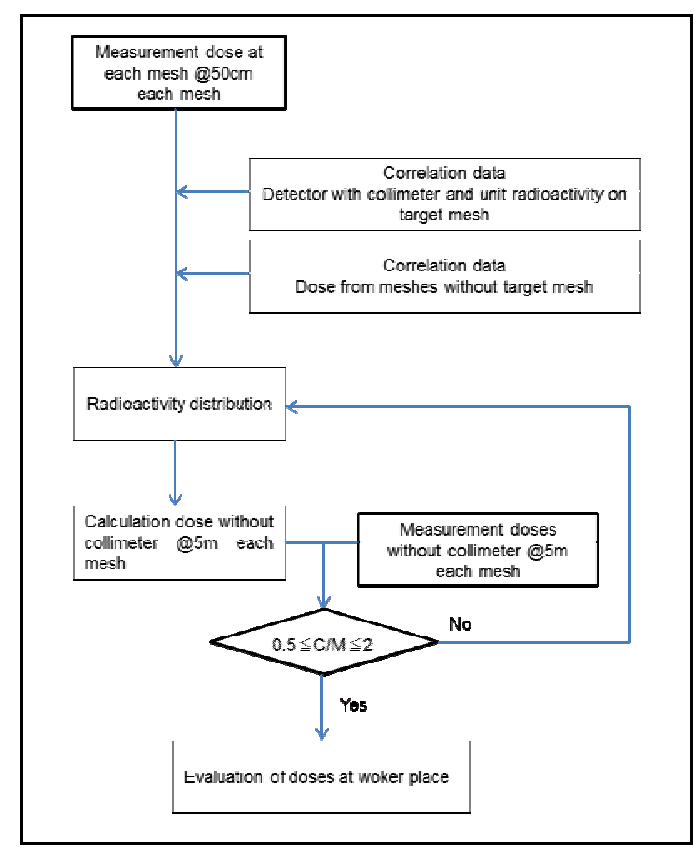

Fig.6. Flowchart of source distribution evaluation

\subsection{Database of relation of radioactivity and location}

It is necessary to evaluate the relationships between unit radioactivity of all 130 meshes and the calculated dose rates at the detector for all 130 meshes in advance to be able to quantify the source strength quickly. However, there were more cases needed to be calculated than could be accommodated by the schedule. In addition, the collimator had rectangular shape making it difficult to reproduce its orientation in the model geometry when measurements were being done by crane.

Accordingly, the relationship of the dose rate with the collimator and planar ring radiation source were evaluated by changing its radius from $0 \mathrm{~m}$ to $61 \mathrm{~m}$ and the results were used to create a database. This calculation geometry was similar to that shown in Figure 4.

Next, a small tool was created which can almost automatically evaluate the source strength of the target mesh using the procedure shown in 3.1. The tool extracts data depending on the distance between the detector within the collimator and the center of the target mesh. 
Another challenge was that much of the operation floor was not flat or had collapsed. It was supposed that the source was mesh planar because the source distribution was used to evaluate dose rates at the workplace on the shield floor and therefore the planar source assumption was deemed acceptable.

For these calculations, the gamma ray spectrum was based on Cs134, Cs137, and Ba137m. "MCNP5" was used for the calculations with the "MCPLIB04" library and point detector tally F5. The flux to dose conversion factor from "ICRP Publication 74" was used.

\subsection{Detector for Validation of evaluated source distribution}

To validate the calculated source distribution, a detector without a collimator was set $5 \mathrm{~m}$ above the operation floor and the dose rates with the collimator were measured at the same time. Measured dose rates at $5 \mathrm{~m}$ without the collimator were compared to calculated dose rates using the calculated source distribution.

The database mentioned in 3.2 and 3.3 is shown in Figure 7 for information. These are normalized by a dose rate at $0 \mathrm{~cm}$ of a distance from the center of $\mathrm{GM}$ counter to radiation source.

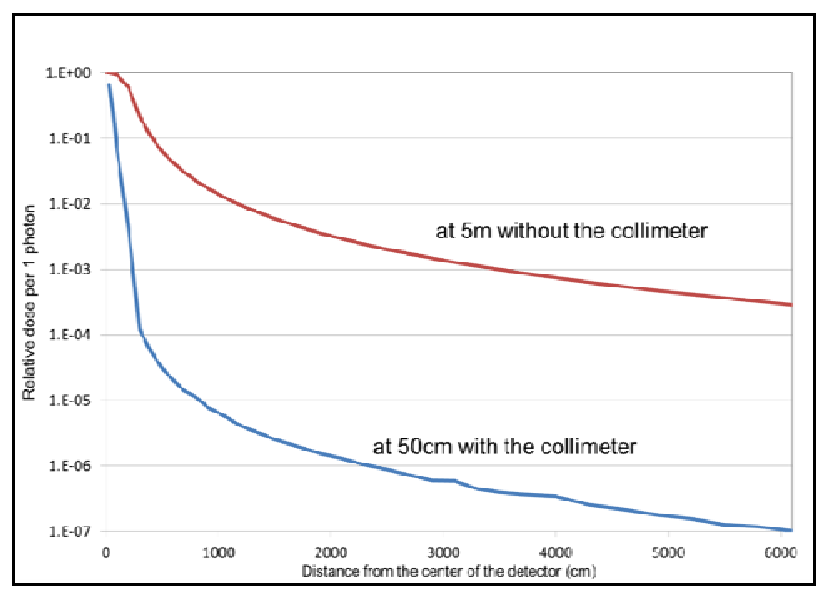

Fig.7. Relative radioactive distribution on the operation floor of Unit3

\subsection{Evaluated source distribution}

The first measurement after removal of the large debris was done on November, 2013. The source distribution was calculated using the procedures previous mentioned is shown in Figure 8. This map shows the ratio of the largest dose rate area ("Red" in the map) to the others.

As a result of the map, the presence of a high radiation field in the meshes around the well plug. There are gaps between the plug and the floor with a couple of $\mathrm{cm}$. The largest dose rate area is considered as the part of to which radioactive materials were strongly stuck by radioactive-gas-burst through a gap between the wellplug and the floor.

In addition, the dose rates at $5 \mathrm{~m}$ were calculated using the evaluated source distribution and $\mathrm{C} / \mathrm{Ms}$ were calculated. The results are shown in Figure 9. The results show that the $\mathrm{C} / \mathrm{Ms}$ were in the range of $1.0 \sim 2.4$. In particular, $\mathrm{C} / \mathrm{Ms}$ in the higher dose rate area around the shield plug were 1.0 1.3. Using this distribution, calculated dose rates would be conservative since almost all $\mathrm{C} / \mathrm{Ms}$ were over 1.0. There were meshes which $\mathrm{C} / \mathrm{M}$ were over 2.0 on outer edge and these $\mathrm{C} / \mathrm{Ms}$ were attributed to higher settings of meshes around the wellplug. The high $\mathrm{C} / \mathrm{Ms}$ had no impact on the dose rates at the workplace and this radiation distribution was available since the source strengths at the outer edges were relatively lower than other areas and the measured dose rates have a variation from measurement due to the crane operation.

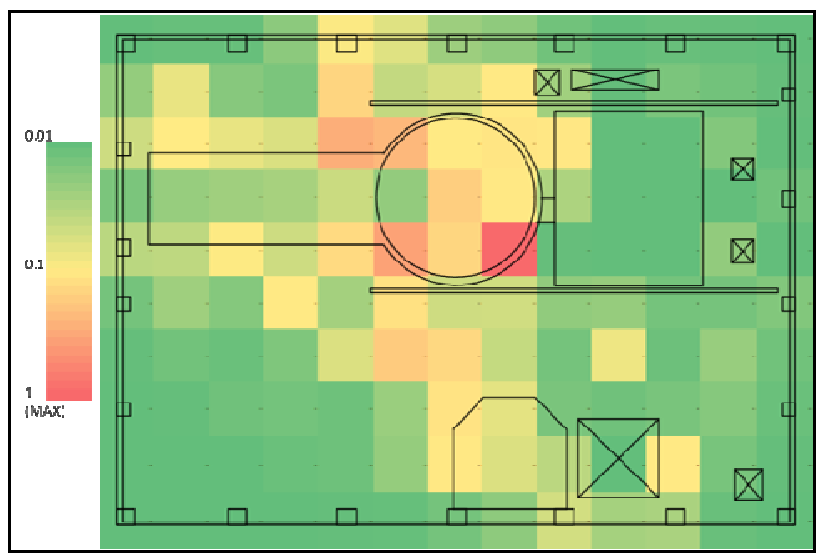

Fig.8. Relative radioactive distribution on the operation floor of Unit3

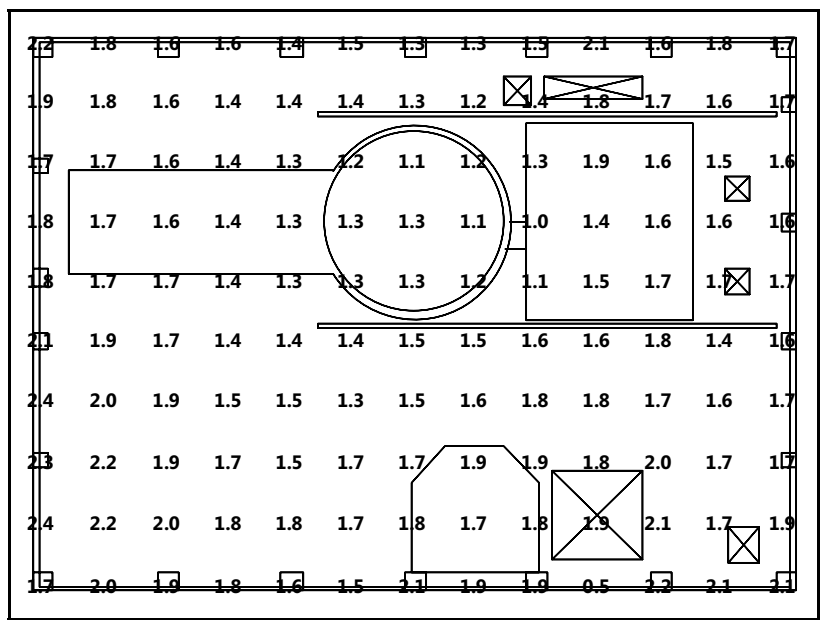

Fig.9. Ratios of calculated dose rates to measurement dose rates at $5 \mathrm{~m}(\mathrm{C} / \mathrm{M})$

\section{Evaluation of dose rates at workplace}

\subsection{Planned shields on the operation floor}

Because the workers will be on the operation floor, the iron floors of $65 \sim 250 \mathrm{~mm}$ had been planned for use as shielding before the removal of the large debris and measurement. These shields were constituted of reedshaped parts and the parts would be installed by crane. The planned shields are shown in Figure 10. 


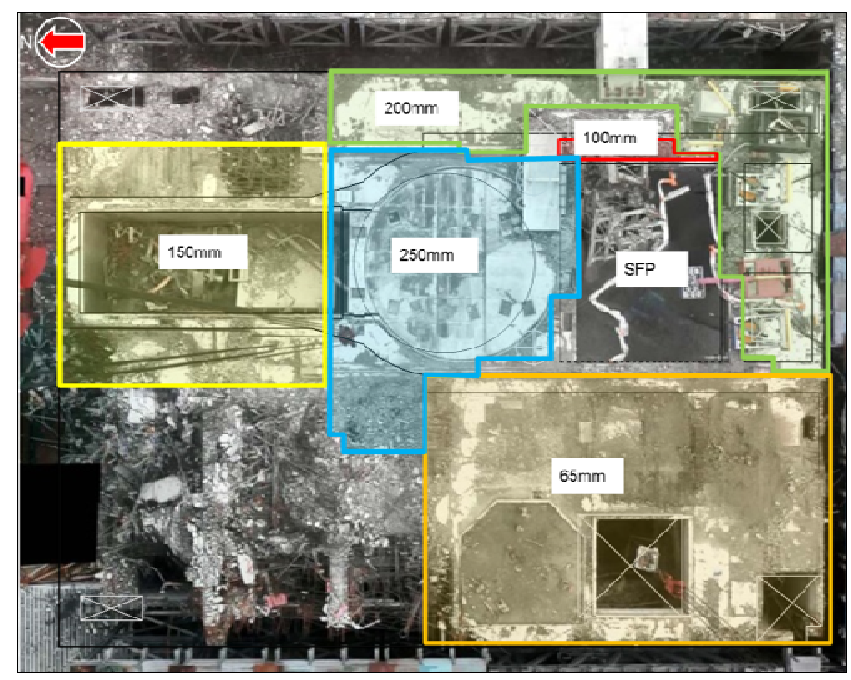

Fig.10. Planned shields on the operation floor with its thickness

As shown in Figure 2, the FHM and the workplace will be installed on the SFP. The floor of the workplace will be located at $6 \mathrm{~m}$ above the operation floor while a installing a girder for the FHM. The dose rates at the workplace at $7 \mathrm{~m}$ above the operation floor considering the height of a person were calculated using "QADCGGP2R" [4] and the calculated source distribution.

\subsection{Evaluation of the dose rate at workplace}

It was found that the dose rates at some points were above the target dose rate of $1 \mathrm{mSv} / \mathrm{h}$. The main causes were gaps between the shields and the operation floor and the inability to install more shielding due to the vulnerability of the building. Therefore, it was decided that additional shields should be designed to be installed in the structurally sound areas and that the smaller debris should be decontaminated.

In addition, debris outside of the reactor building and radioactive materials stuck on the walls would have to be considered following another measurement.

\subsection{Examination of the dose rate from a gap between the shield floors}

As shown Figure 10, shields in the northwest side were not planned before the workplace dose rate evaluation. However it was found that about $5 \mathrm{~cm}$ thick lead shields were needed for the northwest area despite the northwest area having relatively lower source strengths. It was impossible to directly install shields in the northwest area due to the structural integrity of the building. Therefore a shield structure which used the dryer and separator pit and the gantry for support was adopted.

The shields will consist of gutter shape parts the same as the other shield floors and the installation crane will allow gaps of about $45 \mathrm{~mm}$ between the parts on average. There is no workplace on these shield, however there are workplaces on the neighboring shields. The impact of how gaps between the shielding effect doses were calculated. Dose distributions at $7 \mathrm{~m}$ and $3.2 \mathrm{~m}$ from the operation floor and $1.2 \mathrm{~m}$ from the shields normalized by the doses at the center of the gap are shown. Increases, which width of increase was $40 \mathrm{~cm}$ at most were found around the gap, and the gap had little influence on the workplace.

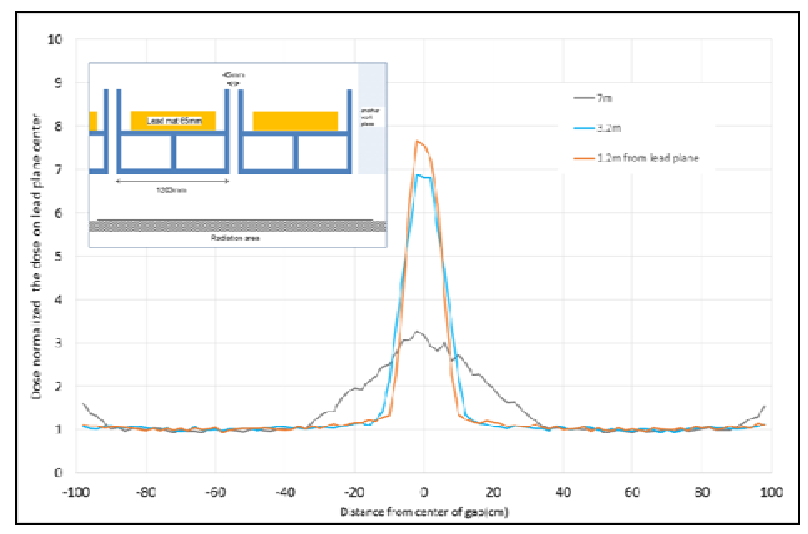

Fig.11. Dose rates normalized by dose rates on the center of the gap

Moreover, additional shields for use in the gaps between the shields and the operation floor were evaluated from the perspective of preventing gamma rays from reaching the workplace directly. In addition, a radiation distribution of the debris outside of the reactor building and the presence of radioactive materials on the wall were evaluated using the measured dose rate. Shields between the reactor building and the gantry were also examined.

The decontamination work on the operation floor and SFP also reduced the dose rate. To check a progress of the decontamination work and to decide whether to install the FHM and the shield floors quickly, another database of the dose rate at the workplace after installation of the shield floors per unit radioactivity $\left(\mathrm{Bq} / \mathrm{cm}^{2}\right)$ was prepared. The dose rates could be calculated using only the change in the evaluated source distribution.

Measurements have been done several times and the dose rates have been used effectively for the planning of the work over the operation floor.

For all of this work, the dose rates in the workplace mentioned in 4.1 were confirmed to be below the 1 $\mathrm{mSv} / \mathrm{h}$ dose rate target calculated. However there were over $1 \mathrm{mSv} / \mathrm{h}$ areas in some phases of the shield and FHM installation. Temporary shields and reduced work time would be examined for dose rate reduction of the workers.

As of August 2016, almost all of the shields shown in Figure 10 have been installed. Currently status of shields is shown in Figure 12. 


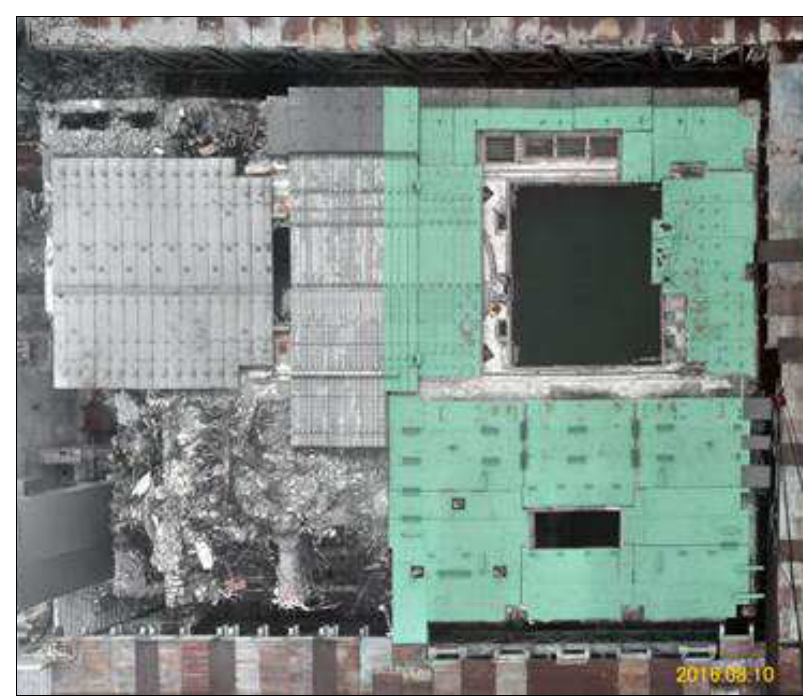

Fig.12. The situation for the Shields as of August 2016

\section{Conclusion}

Using measurement data obtained with a collimator, reasonably accurate dose rates and source distributions could be calculated for the operation floor of Fukushima Daiichi Unit 3.

In addition, by developing dose rate databases based on unit radioactivity $\left(\mathrm{Bq} / \mathrm{cm}^{2}\right)$ it is possible to calculate new dose rates using only the change in source distribution.

\section{Summary}

Using a collimator for dose rate measurement, radiation concentration in any site can be evaluated from the measured dose rates like in this case. However, designing a collimator suited for the situation will be needed.

Product names may be trademarks of their respective companies.

\section{References}

1. X-5 Monte Carlo Team, MCNP - A General Monte Carlo N-Particle Transport Code, Version 5 Volume I: Overview and Theory, LA-UR-03-1987, (Revised $2 / 1 / 2008)$

2. M. C. White, Photoatomic Data Library MCPLIB04: A New Photoatomic Library Based on Data from ENDF/B- VI Release 8, Los Alamos Laboratory internal memorandum X-5:MCW-02111(2002)

3. ICRP, Conversion Coefficients for use in Radiological Protection against External Radiation, ICRP Publication 74, Annals of the ICRP26(3/4), Pergamon Press, Oxford, (1996).

4. Y. Sakamoto and S. Tanaka, QAD-CGGP2 and G33-GP2 : Revised Versions of QAD-CGGP and G33-GP Code with Conversion Factors from
Exposure to Ambient and Maximum Dose Equivalents, JAERI-M 90-110, (1990) 